\title{
Avaliação do serviço de saúde bucal no município de Grão Mogol, Minas Gerais, Brasil: "a voz do usuário"
}

\author{
Evaluation of oral health service in Grão M ogol city, \\ state of M inas Gerais, Brazil: "the users' voice"
}

Claudiojanes dos Reis ${ }^{1}$

Hercílio M artelli-Júnior ${ }^{1}$

Bárbara M elo Franco ${ }^{2}$

Almira Alves Santos ${ }^{3}$

Luciana M aria Pedreira Ramalho ${ }^{4}$

1 Instituto Ciências da Saúde Faculdade de Odontologia, FUNORTE. Av. Osmane Barbosa 11.111, Bairro JK. 39400-000 M ontes Claros MG.

claudiojanes@yahoo.com.br ${ }^{2}$ FUNORTE.

${ }^{3}$ Universidade Estadual de

Ciências da Saúde de

Alagoas.

${ }^{4}$ UniversidadeFederal da

Bahia.
Abstract The objective of this study is to evaluate the oral health services in the city of Grão M ogol, Brazil by analyzing the user's perceptions. It was chosen the qualitative methodology using a semistructured interview. The aspects investigated included the perception of the process of oral health/ illness; knowledge, practices and value attributed to oral health; access to services; professional/patient relationship and assistance received. The interviews wereanalyzed and the central ideas extracted, which were considered in a final analysis of the study. It was observed that the oral health service in this city is going through a period of changes, but it still exist an iatrogenic-mutilator practice. However, health prevention and promotion gains space within health actions, acting as important factors to enhance oral health assistance and resulting improvement of the population quality of life. U sers can feel the evolution of the service, but admit the necessity of more organization and definition on the access to services as well as an improvement on the communication professional/patient. The population starts to value the oral health as something important within the life conditions of each individual.

Key words Evaluation, Family Health Program, Dental care, Oral health, Dentistry
Resumo Foi objetivo destetrabalho avaliar o serviço de saúde bucal, através do estudo das percepções dos usuários, do município de Grão M ogol - norte de M inas Gerais, Brasil. O ptou-se pela metodologia qualitativa, utilizando entrevista semi-estruturada. Foram levantados aspectos sobre percepção do processo saúde/doença bucal; conhecimentos, práticas e valor atribuído à saúde bucal; acesso aos serviços; relação profissional/paciente e assistência recebida. Obtiveram-se as idéias centrais em cada tema abordado nas entrevistas, sendo posteriormente agrupadas eanalisadas, constituindo a análisefinal do estudo. Observou-se que o serviço de saúde bucal, no município, vive período de mudanças, mas existe ainda uma prática iatrogênica-mutiladora. No entanto, a prevenção e a promoção da saúde ganham espaço entre as ações de saúde, atuando como importantes fatores para a melhoria da assistência à saúde bucal e consequente melhoria na qualidade de vida da população. Os usuários percebem a evolução do serviço, mas admitem a necessidade de seorganizar e definir melhor o acesso aos serviços e otimizar a comunicação profissional/paciente. A população começa a valorizar a saúde bucal como al go importante dentro das condições de vida de cada indivíduo. Palavras-chave Avaliação, Programa Saúde da Família, Odontologia, U suário, Saúde bucal 


\section{Introdução}

O Sistema Ú nico de Saúde (SUS) é uma proposta de reorganização dos serviços de saúde, que se encontra ainda em fase de estruturação, apesar dos avanços conquistados. Essa construção sofreu influência de momentos históricos, políticos e econômicos do país. Os avanços e recuos foram frutos de grandes lutas político-ideológicas em que se envolveram diferentes atores sociais, que resultou, portanto, em amplo debate democrático ${ }^{1}$.

Com o advento do SUS, tem-se priorizado a instituição de modelos assistenciais em saúde bucal centrados nos princípios que o norteiam: integralidade, universalidade, equidade, descentralização das ações e controle social. Esses programas ainda estão em fase de consolidação ${ }^{2,3}$. Dentre esses modelos de assistência, destaca-se o Programa Saúde da Família (PSF), que busca a reorganização do sistema, bem como a reordenação das práticas sanitárias vigentes 4 . Os serviços de saúde bucal herdaram padrões de práticas que paralisam 0 fazer cotidiano dos trabalhos para a saúde, o que dificulta a inserção da odontologia no SUS, sobre tudo quando se trata de modificação do modelo de atenção. É necessário que se reflita o modelo a ser desenvolvido de forma participante, com todos os atores sociais envolvidos nesse processo ${ }^{5}$.

0 que se verifica é que a odontologia se caracteriza pelo avanço, cada vez maior, no sentido de se estabelecer novas tecnologias, tornando-a mais eficiente e apresentando mais variáveis como forma de solucionar os problemas de saúde bucal da "população" ${ }^{\text {. }}$. Mas o que ainda se observa é a presença de doen ças controláveis, como a cárie dental e doenças periodontais, atingindo considerável parcela da população 7 . Rego et al.$^{8}$ afirmaram que os principais problemas de saúde bucal da população são possíveis de serem erradicados, desde que haja a instituição de uma filosofia preventiva e programas efetivos de promoção de saúde.

0 processo saúde-doença é caracterizado conforme a época na qual se estabelece. A percepção deste, voltado ao indivíduo, baseia-seno seu modo de vida e abrange uma variedade de contextos marcados por diferenças culturais, sociais, econômicas e individuais ${ }^{8}$. M inayo ${ }^{9}$ relatou que, mesmo com a especificidade do setor saúde, a saúde não está desvinculada da problemática social mais ampla e, nesse contexto, os usuários exercem papel essencial nos programas de assistência à saúde. Segundo Bosi e Affonso ${ }^{10}$, eles estabelecem uma relação cotidiana com os serviços de saúde e com profissionais que aí atuam. Essa ação vai além da simples procura pelo serviço, inscreve-se numa prática pluridimensional e assume uma dimensão política. No entanto, a subjetividade dosindivíduos no processo é, geralmente, esquecida nos planos e programas do setor saúde. Baseado na relação que os usuários exercem nos programas assistenciais de saúde, este estudo objetivou analisar sua participação na reestruturação e consolidação do sistema de saúde.

\section{M etodologia}

A abordagem do presenteestudo équal itativa, utilizando-se a técnica de entrevista semi-estruturada e a observação direta. Esse procedimento possibilitou ao entrevistado logicar sobre o tema abordado, ainda queessa técnica não estruture completamente o domínio de investigação. Descreveu-se o serviço de saúde bucal em Grão M ogol, visando caracterizar a assistência à saúde bucal do município através da representação do processo saúde/doença dos usuários, bem como a participação desses nas resoluções dos problemas de saúde bucal, forma de compreensão do atendimento odontológico, suas dificuldades, prioridades, necessidades, expectativas e desejos. No processo de análise dos dados, resgataram-se as representações individuais para cada questão abordada no roteiro. Posteriormente, realizou-se a categorização dos dados, buscando-se a descrição das idéias centrais em cada tema no discurso de cada sujeito. Posteriormente, elas foram agrupadas em um único discurso, um discurso-síntese de todos os indivíduos que compõe o sujeito coletivo, o que possibilitou a fundamentação para estabelecer as conclusões. Este estudo foi aprovado pelo Comitê de Ética em Pesquisa da Universidade Estadual de M ontes Claros, UNIM ONTES.

Este estudo foi desenvolvido junto aos usuários do serviço público do município de Grão M ogol (zona urbana e rural), norte do Estado de Minas Gerais Brasil. A seleção dos locais onde seriam realizadas as entrevistas se deu de forma al eatória, por meio de sorteio, envolvendo a sededo município ezona rural.

Foram entrevistados 26 usuários do serviço público municipal de saúde bucal das unidades de saúde locais, na faixa etária de 25 a 67 anos. A escolha dos entrevistados se deu de forma a contemplar os moradores mais antigos das regiões sorteadas, bem como os usuários que estavam frequentando as unidades e que aceitassem participar da pesquisa para uma caracterização eanálise da possível evolução ou não do serviço de saúde bucal. Por se tratar de perspectiva qualitativa, na definição da amostragem, não foram colocadas questões como representatividade, 
verificabilidade ou generalização, dentre outras questões comuns à abordagem quantitativa. Buscou-se neste estudo um aprofundamento da compreensão dos usuários envolvidos na pesquisa, não obedecendo a um critério numérico. De acordo com M inayo ${ }^{9}$, a amostra ideal é aquela capaz de refletir a totalidade nas suas múltiplas dimensões visto que "[...] cada agente, ainda quenão saiba, ou não queira é produtor de ações que caracterizam um grupo".

$\mathrm{N}$ a definição da amostragem, buscou-se abranger todo o problema investigado, sendo a questão da validade da amostra assumida a partir desse fato, visto que se considerou suficiente o número de entrevistas no momento em que se esgotaram as categorias abordadas no discurso dos entrevistados.

\section{Resultados}

Não tinha outro jeito de tratar: extração como única al ternativa e uso de prótese total para voltar à "boniteza"

0 sofrimento às vezes era tamanho que as pessoas faziam uso de práticas terapêuticas diversas, variando desde medicamentos industrializados, quando os tinham, até as receitas populares.

A gente colocava até sal no dente, fogo também, quejá usei. E usei também uma época um "Passajá".

A terapêutica à base de medicamentos industrializados assumia um caráter rotineiro, no qual a automedicação era mais que uma necessidade, representando a única forma de sever livre do processo doloroso. Entretanto, para a população rural, mesmo os medicamentos industrializados eram de difícil aquisição, mostrando a dificuldade de acesso às ações relacionadas à saúde:

$\mathrm{Na}$ época, a gente tomava dipirona, mas não adiantava nada não. 0 remédio era rancar.

M edicamentos alternativos eram utilizados constantemente de forma a aliviar a angústia, 0 sofrimento e, para aumentar sua eficácia, era adicionado o "fator divino", que consistia na maior fonte de esperança de se livrar da dor:

Quando eu era pequena, minha mãe ponhava criolina na minha boca, rancava o coro tudo e o denteficava a mesma coisa. Só parou de doer quando rancou.

Tinha buchechada que a gente fazia. A buchechada, a gentecolocava fumo, colocava hortelã, cinza defogão à lenha . Aí a gentetuntiava ea raiz do dente também durmecia. A base de Deus resolve.

A assistência à saúde bucal no município de Grão M ogol há muito se caracterizou pela prática iatrogênica e mutiladora:
Ranquei tudo.

$\mathrm{N}$ em pensava quetinha essa forma quepodia tratar dos dentessem ser rancado, num sabia não, depois é que a gente já foi ficando sabendo que já tinha.

Como resultado dessa prática odontológica, parte considerável da população do município, com faixa etária acima dos 40 anos, encontra-se parcial ou totalmente edentada e vêem na prótese um paliativo que, na maioria das vezes, não satisfaz as necessidades estéticas nem funcionais. Alguns usuários de prótese total mostraram-se frustrados devido à perda precoce dos seus dentes:

Eu acho assim que dentadura éo seguinte, usar ela eu acho que só se for pra boniteza, mas pra dizer que é bom num é não.

Faz falta, muitas coisa eu acho ruim, né, sobre mastigar, chupar uma cana eé mais ruim, num é a mesma coisa. Até sobre conversar mesmo, tem hora que cê vai gritar ela tá folgano quereno cair.

\section{0 acesso ao atendimento}

$\mathrm{Na}$ avaliação dos usuários, o acesso é influenciado por diversos fatores, destacando-se: fator geográfico (distância), ausência de infra-estrutura, ausência de serviços, qualidade do atendimento e presença de vagas; fatores que dificultam a acessibilidade aos serviços e, consequentemente, a resolução dos problemas de saúde bucal. Diversas vezes são citados municípios limítrofes a Grão M ogol, como Francisco Sá e Fruta de Leite, onde, em relação à distância, o acesso se tornava mais fácil, o que justificava a procura por eles:

Quando não tinha estrada, era muito difícil, era uma dificuldade sem fim mesmo.

Tinha vez que eu tinha que rachar no pé, ir pra Fruta de Leitequeéum absurdo delonge, era um dia inteiro de viagem a pé, eu tinha de ir pra distrair meu dente.

A questão do atendimento foi citada como importante componente que envolve 0 acesso, podendo interferir nesse de modo a aumentar 0 sentimento de desprezo nas pessoas atendidas, ou tornar 0 acesso ao serviço mais facilitado. 0 crité rio de escolha dos pacientes também foi um aspecto focalizado, pois nem sempre prevalecia a necessidade do tratamento:

Num satisfazia a gente muito, muito não. Tinha vez que cê chegava lá, ficava assim, num sei se fazia muita hora da cara da gente. Tinha umas pessoas que era ótima, a genteia chegano ecêjá ia arrumano logo.

Em todo meio político tem, acho que pra certas pessoas dificulta sim, porque eu conheço pessoas que receberam o tratamento de graça, e tem gente que já precisa e não conseguiram. 
Isso se torna uma preocupação dos próprios usuários que chegam a sugerir formas de melhorar esse acesso, garantindo a sua equidade. A listagem de pacientes submetidos ao tratamento éfeita pela secretaria municipal de saúde, a partir delivre demanda dos pacientes, sem uma triagem prévia nos consultórios odontológicos. Essa evidência fica demonstrada na fala abaixo:

Eu acho quedeveria ser feito em relação a seleção, o próprio diagnóstico, dar a oportunidade das pessoas defazerem uma avaliação, porqueeu sei degenteque já procurou, que precisa e muito, e não conseguiu, e gente que não precisa e não dá aquele valor, e consegue. Os próprios dentistas fariam a avaliação.

\section{Conceituando a saúde \\ e entendendo a doença}

No discurso dos usuários avaliados, a saúde aparece com um conceito mais amplo, ultrapassando a dimensão biológica. Os entrevistados apontam determinados domínios de nível natural, psicossocial, socioeconômico e sobrenatural, relacionando-os com o processo saúde-doença:

É ter saúde, éviver em paz com minha família.

A saúde é uma coisa muito importante porque sem ela a gente não énada, né?

Eu acho que saúde seria talvez não só simplesmente ausência de doença, né, mas condição também pra se viver, né? Acho que saúde seria se a pessoa às vezes também não tem uma condição, uma garantia de às vezes fisicamente se está ótimo mas emocionalmente não tá devido às di ficuldades, seus direitos não estão sendo garantidos, às vezes falta emprego.

Os aspectos do "estar doente", relacionados aos fatores sociais e à espiritualidade (D eus), abordados nas falas, vêm evidenciar o cotidiano das pessoas. Isso pode se observado pela forma como os usuários definem doença:

Tá doenteé quando vocênão tá bem com o meio externo, você não tá bem fisicamente, você não tá bem mentalmente, doença geralmente você tá diferente do normal.

Quando eu tô doente, faço orações. É só D eusque resolve os nossos problemas.

A limitação para realizar trabalho adquiregrande importância no contexto de vida dos usuários:

É muito ruim né. $\mathrm{N}$ em jeito de trabalhar num tem.

A percepção do usuário sobre a saúde bucal

A população começa atribuir maior importância à saúde bucal, eliminando a dicotomia saúde bucal/saúde geral:
Eu num sei se eu tô certa, mas pra mim a saúde bucal équase a mesma coisa como se fosse a saúde de qualquer parte do corpo, né, porque saúde bucal faz parte também.

Então a saúde bucal vê o individuo como um todo, né

Eu acho queémaisfino né, por causa quea saúde da boca, aténo conversar com uma pessoa, se ocêtiver um mau hálto (hálito) na boca, se tiver um dente cariado, um dente estragado, já atrapalha.

Os entrevistados apontam uma associação entre saúde bucal eautocuidado, com este assumindo uma maior importância na manutenção da saúde.

Saúde da boca étratar os dente, escovar os dente, éisso que é saúde.

A "estragação" dos dentes ea dor:

percebendo os problemas de saúde bucal

e a busca pelo atendimento

Os usuários do serviço reconhecem a "estragação" dos dentes a partir de fatores como a placa bacteriana, dieta, saliva e falta de acesso ao flúor, mas, popularmente, utilizam sinônimos e a placa se transforma em "sujeirinha", bactéria em "minhoca" e várias outras denominações para a destruição dos dentes por cárie:

Aí fica aquela sujerinha, pega nos dente e aí vai cariando tudo ejá começa estragá os dente e eu acho quetirano aquela coisa quefica aí num estraga muito os dente.

Isso pode dar algum negócio dentro, uma minhoca, esses negócios que come dente.

Pode ser algum chicrete, bala, doce isso pode estragá os dente, né.

Além dos fatores biológicos citados como causa da "estragação", os entrevistados ainda citam fatores relacionados ao cotidiano:

Naquele período, a gente não procurou porque acho que nem se quer tinha uma forma de (tratar), orientações, não tinha ações assim pra resolver instantaneamente aquela questão, mas tanto é que eu nem me lembro de dentista naquela época pra falar pra mim: 'Oh, cêtá escovando os dentes regularmente? 0 u, o que que cêtá fazendo?' A té porque também acho que as orientações dele dificilmente iam ser obedecidas por mim pela condição financeira.

A presença ou ausência da dor como indicativo da presença ou ausência de doença pode ser inferida na fala dos usuários, apresentando-se como principal fator de detecção e mobilização para os cuidados relacionadosaos problemas desaúdebucal, chegando a promover mudanças comportamentais:

Dor de dente e muita cárie. Foi a dor. Enquanto tinha cárie mas não tinha dor eu tava no meu canto. 
Cê perdia até a cabeça, cê pensava até coisas errada de tanta dor de dente.

M uitas vezes, o sofrimento causado pela dor de dente e o sentimento de perda após a extração do mesmo mobilizam as pessoas a refletirem sobre a importância de preservarem os dentes e o cuidado com os seus descendentes para que não sejam vítimas da "vida sofrida" pelo qual passaram:

Por causa do sofrimento que foi antes, né, muitos têm a curiosidade na idéia de falar com os filhos: 'Ó meu filho, eu sofri tanti com dor de dente então a gente luta pra vê se ocês num tem essa vida sofrida que a gente sofreu'.

Os entrevistados, em idade mais avançada, aceitam a crença de que os problemas bucais esuasincapacitações são consequências inevitáveis da idade:

Eu não quero dar trabalho pra ninguém, já estou velho. Eu não quero amolar os outros, agora vou só esperar as ordens de Deus. Eu penso assim, essa dentadura não vai valer mais nada.

\section{A importância da relação}

profissional/paciente

Os entrevistados admitem ser importante a relação interpessoal entre profissional e paciente, tendo influência sobre o resultado do tratamento:

Com certeza o bom relacionamento influencia pra melhor. Então eu acho que isso influi pra meIhor, contribui.

É bastante perceptível na fala dos usuários o aspecto relacionado à educação, cordialidade, gentileza e comunicabilidade como fatores importantes para o restabelecimento da saúde, mas salientam o significado positivo de receber uma atenção maior, um gesto de carinho.

Tinha que ter cum carinho cum a gente também, né. Paciência e saber responder o paciente.

Interferia, né! Q ue acontece se ocê tiver doente e uma pessoa chega convesano com você, você distrai mais, né, você tira aqueles pensamente ruim que vocêtá pensano. Ajuda desenvolver mais.

\section{A prevenção na visão do usuário}

M esmo com toda sua utilização, o flúor ainda não étotalmenteconhecido pela população e, quando o é, não se compreende ao certo a sua ação:

$\mathrm{Na}$ escola éfeito. Eles põe os meninos pra escovar os dente, eles aplica um remédio na boca dos meninos (flúor).

Eu acho que é pra limpar melhor os dentes. Eu acredito que adianta muito porque o flúor quando aplica fica todo avermelhadim, né, tem hora que a pessoa nem tá vendo a sujeira ondetá, eondea sujeira tá é onde agarra, né".

Os usuários apontam o autocuidado, a prevenção ea promoção da saúde como fatores importantes na diminuição da incidência de doenças bucais, mas salientam a necessidade de uma associação de fatores como escovação, flúor, uso do fio dental e participação dos odontólogos neste processo:

Pela falta de cuidado que eles [filhos] têm, eu acho que acelerou muito o processo. Eu acho que faltou muita prevenção.

Se num escovar, aquele limo que junta nos dentes faz o dente cariar, faz pudrecer.

A gentemesmo tem queter um pouco também de experiença, junto com o dentista também pra orientar a gente.

A evolução do serviço de saúde bucal:

as marcas e expectativas

U mas coisa melhorou de antigamente e outras tá do mesmo jeito, né. Antigamente, um problema de saúde a pessoa sofria mais do que hoje.

N os caminhos construídos pelo serviço de saúde bucal em Grão M ogol, constatou-se uma mudança no modelo de assistência: a transição deuma fase caracterizada pelo curativismo (exodontia), com assistência precária à população, para as práticas intervencionistas que atualmente ocorrem junto com as preventivas, demonstrando a evolução desse serviço. A baixa resolutividade das ações de saúde é bastante perceptível no discurso dos entrevistados:

$\mathrm{Na}$ época, era um pouco meio difícil pra gente tratar, tinha muita dificuldade da gente chegar até na cidade.

Tive que extrair dentes na época da minha adolescência e pelas dificuldades, né, financeiras e tudo, eu não pude na verdade fazer o tratamento, eu tive que fazer extração.

Essa precariedade foi manifestada na caracterização do serviço desaúde (o passado), feita principal mente pel os moradores mais antigos da zona rural, que revelaram sentimentos dos mais diversos, como dor, sofrimento, angústia, até que "voltava ficá bom outra vez", ou então mandava "distraí". As dificuldades financeiras foram um dos aspectos recorrentes nos depoimentos:

Antigamente, num fazia nada, ficava assim mesmo. Porque num tinha como fazê nada. 0 dentista era muito difícil, quando aparecia o dentista num tinha o dinhei ro pra pagá.

O serviço odontológico no município apresenta uma transformação com o passar do tempo, 
com o desenvolvimento de ações de caráter curativo e preventivo, que aumentam a satisfação dos usuários:

Eu acho que tá ino muito bem, tô sentino muito feliz com esse trabalho. Eu acho que melhorou.

Eles põe os meninos pra escovar os dente, eles aplica um remédio na boca dos meninos (flúor).

\section{Discussão}

Grão M ogol se destaca no cenário turístico de M inas Gerais como importante centro histórico e natural do norte de M inas Gerais. Atualmente, 0 município possui dois distritos - Barrocão e Vale das Cancelas - e uma população total de 14.810 habitantes, com $70 \%$ destes residindo na zona rural (vilarejos, fazendas esítios) e uma área total de $4.602 \mathrm{Km}^{2}$, resultando em baixo índice demográfi$\mathrm{CO}^{11}$. A análise dos dados epidemiológicos do município apresentou diferença considerável entre o índice CPOD da zona urbana e zona rural. Tomando-se como exemplo o CPOD aos 12 anos, em 2003, foi de 3,08 e 5,52 na sede do município e zona rural, respectivamente, o quese pôdeinferir a existência de um atendimento menos efetivo na zona rural, em detrimento da sede $\mathrm{e}^{11}$, embora ambos os valores não alcancem o recomendado pela OM S para o ano 2000, que é um índice CPOD menor que três aos 12 anos de idade ${ }^{12}$.

A assistência à saúde, na percepção dos usuários, vive um processo de mudanças, com melhoria no atendimento. Essa evolução do sistema público de assistência à saúde assume uma dimensão nacional, até chegar aos dias atuais, quando se procura garantir os princípios de equidade, integralidade, universalidade, descentralização das ações e controle social, preconizados pelo SUS, ainda que os programas de assistência à saúde estejam em fase de consolidação $0^{2,3}$.

A realidade do serviço de saúde mostra a necessidade de ações intersetoriais, com o PSF assumindo o papel principal nesse processo de mudança, permitindo maior conhecimento das condições de vida de uma população assistida através de ações multidisciplinares e intersetoriais ${ }^{4,13,14}$. 0 sofrimento apresentado pelos entrevistados, às vezes, instigava- os a utilizarem práticas terapêuticas diversas, desdemedicamentos industrializados, quando os tinham, até as receitas populares, conforme estudos apresentados por Nuto ${ }^{15}$. Essas práticas populares assumem determinado valor com eficácia química e simbólica, sendo algumas farmacologicamente comprovadas em casos de infecções bucais e dor de dente ${ }^{15,16}$.
Existem, normalmente, duas circunstâncias as quais fazem com que as pessoas recorram ao autotratamento: quando consideram o problema como corriqueiro, trivial no cotidiano, vendo-se capaz de diagnosticar e prescrever para tal caso; ou pela inexistência ou impossibilidade de acesso aos serviços de saúde, o queé comum no modelo de assistência odontológica verificado no país ${ }^{17}$. A assistência à saúdebucal no município de Grão M ogol, não obstante a realidade brasileira, há muito se caracterizou pela prática iatrogênica-mutiladora, que pouco contribui para melhoria das condições de saúde bucal da população. A prática odontológica hegemônica, curativa emutiladora, constitui a experiência das pessoas em relação aos cuidados em saúde bucal $^{3,18}$. Isso reflete na percepção das pessoas de quea doença era inevitável ea exodontia era aúnica forma de cura, o que foi mudando com o tempo. 0 resultado da prática odontológica verificada anteriormente é a disfunção do aparelho estomatognático da população, que se apresenta parcial ou totalmente edentada, principalmente em faixas etárias mais elevadas. Essa população vê na prótese um paliativo que, na maioria das situações, não satisfaz as necessidades estéticas nem funcionais. M esmo tendo o dente como elemento dispensável do corpo, al guns usuários reconhecem sua falta, apontando uma frustração devido a sua perda $a^{3,7}$.

A inoperância dos serviços de saúde bucal era reflexo da falta de incentivo. As ações relacionadas a esses serviços na maioria das vezes restringiamse aos procedimentos de exodontia e alívio de dor, concordando com estudos de M artins ${ }^{7}$. Esses resultados mostram a presença de impedimentos físicos e financeiros relacionados ao serviço prestado, como dificuldade em conseguir atendimento. Dessa forma, o acesso também deve ser pensado como componente da aceitabilidade do serviço. 0 simples fato de o serviço existir não significa pronto acesso do usuário; deve-se levar em conta os aspectos geográficos, culturais, econômicos e funcionais que envolvem o serviço prestado ${ }^{7,1}$.

Foram abordadas também no presente estudo questões relacionadas aos critérios de escol ha dos pacientes. De acordo com Nuto ${ }^{15}$, a seleção dos pacientes não deve, necessariamente, se vincular apenas à carência detratamento; 0 contexto sociocultural no qual o usuário está inserido tem papel relevante. No discurso dos usuários estudados, a saúde aparece com um conceito mais amplo, ultrapassando a dimensão biológica, em que são reforçados os vários domínios apontados por $\mathrm{N}$ gokwey, citado por M inayo ${ }^{20}$. Esses domínios de nível natural, psicossocial, socioeconômico e sobrenatural, observados na fala dos usuários, vêm 
corroborar com o conceito de saúde proposto na Carta de $0 t_{t a w a}{ }^{21}$. A limitação para realizar trabaIho adquire importância no contexto de vida dos usuários, pois gera desconforto, sensação de fraqueza e perda das condições básicas para sobrevivência, que é a força de trabalho. Essa limitação, como efeito da doença, advém das consequências pessoais imediatas da doença sobre 0 bem-estar físico, psicológico e social 6 .

o processo saúde-doença, descrito pela população avaliada, assume significados que, mesmo admitindo uma concepção biológica, são colocados como expressão da vida cotidiana, possuindo toda uma inserção contextual, com abordagem cultural, social e pessoal, similar à afirmativa de M inayo ${ }^{22}$ : as concepções de saúde doença se constroem em referência ao lugar e à posição de classe e no conjunto das experiências dadas por um modo de vida particular [...] A história de saúdee doença das pessoas está sempre relacionada com a história global de sua vida, que inclui o trabalho, o salário, as relações sociais, a vida espiritual e moral.

A população começa atribuir à saúde bucal maior importância, eliminando a dicotomia saúde bucal/saúde geral, com a boca assumindo uma dimensão maior, tendo todo um aspecto de socialização, estando vinculada ao corpo e exercendo importante papel como trânsito para a saúde geral ${ }^{7}$. Isso éreflexo da maior assistência à saúde bucal no município, bem como de aspectos relacionados à mel horia da qualidade de vida dessa população. A falta de "postura preventiva" da população relatada por Bosi ${ }^{23}$, num estudo junto a profissionais de saúde, nem sempre é observada no relato dos usuários. 0 que se percebe é a importância da associação entre saúde bucal e autocuidado na manutenção dos níveis de saúde.

A cárie é uma doença de origem bacteriana; pode ser influenciada por vários fatores que potencializam ou amenizam sua ocorrência. Dentre esses fatores, pode-se citar a placa bacteriana, dieta, saliva, acesso ao flúor, além de fatores de nível socioeconômico e nível de conhecimento, que assumem grande importância no processo dessa patologia ${ }^{6}$. Os usuários do serviço reconhecem a "estragação" dos dentes a partir de alguns desses fatores, porém utilizam outros sinônimos, podendo seinferir daí uma associação com termos como lagarta ${ }^{15}$. Entretanto, nota-se também a relação, feita pela população, entre doenças bucais e fatores ligados às suas condições de vida, dando ênfase à pouca condição financeira eà dificuldade de acesso ao serviço?.

A presença ou ausência de dor como indicativo da presença ou ausência de doença pode ser inferi- da na fala dos usuários sobre os problemas de saúde bucal, apresentando-se como principal fator de deteç̧ão e mobilização para os cuidados relacionados aos problemas de saúde bucal, conforme outros estudos ${ }^{15,24}$. Bezerra et al..$^{25}$ afirmaram que a dor é o único meio que possibilita 0 diagnóstico de se estar doente, bem como determina a procura pelo serviço.

Os desequilíbrios nas condições de saúdebucal da população desen cadeiam perturbações comportamentais e 0 aspecto relacionado à dor vem definir o processo saúde/doença bucal. A dor representa um sinal de vida e impõe uma necessidade comportamental de mudanças ${ }^{26}$. Isso, às vezes, mobiliza as pessoas a cuidarem dos seus descendentes para que não sejam vítimas do mesmo episódio, evitando assim a "vida sofrida" pela qual passaram. Esse fato é observado, principalmente, no discurso das mulheres que, uma vez conscientizadas e preparadas, podem assumir o papel de principal agente de saúde na família ${ }^{27}$. O bservouse, no relato de usuárias em idade mais avançada, que a percepção sobre a saúde bucal está relacionada a valores pessoais, relacionando-os à crença de que os problemas bucais e suas consequentes incapacitações são inevitáveis nessa idade, estando em concordância com os estudos de Silva et al. ${ }^{24}$.

É importante ressaltar o valor da relação interpessoal entre profissional e paciente, observada no discurso dos usuários, devendo constituir-se em estratégia que produza comportamentos adequados nesses indivíduos em interação. É preciso que haja no serviço odontológico uma preocupação com o bem-estar físico e emocional do paciente ${ }^{7}$. ${ }^{26}$, pois a prática odontológica é caracterizada pelo contato físico entreo pacientee o profissional. Dada essa peculiaridade da odontologia, 0 ato odontológico adquire um caráter de proximidade, pois está relacionado à manipulação da boca, que possui um alto grau de simbolismo e intimidade.

Os aspectos relacionados à educação, cordialidade, gentileza ecomunicabilidade, além da simpatia, assumem dimensão de maior importância que a competência profissional. Isso é bastante perceptível na fala dos usuários do serviço de saúde bucal em Grão M ogol, que sempre desejam mais atenção, um gesto de carinho, como forma de tornar 0 atendimento mais prazeroso, diminuindo assim a ansiedade, normal no tratamento odontológico. $\mathrm{M}$ artins ${ }^{7}$ assinala que as características sociais tanto de profissionais quanto pacientes estão inseridas nesta relação. Os aspectos religiosos, étnicos, sexuais ede classe social, além do ambiente de trabalho, atuam como componentes subjetivos que influenciam em diagnósticos e planos de tratamento. 0 
diálogo assume importante papel nessa inter-relação efaz com que o usuário sesinta valorizado com esse gesto, poden do contribuir na melhora do estado geral do paciente, bem como tornar o ambiente mais agradável, ganhando assim a afeição e maior participação da população na resolução dos problemas relacionados à saúde bucal 7,26 .

\section{Consideraçõesfinais}

A partir da análise dos resultados deste estudo, observa-se que o serviço de saúde bucal no município de Grão M ogol, localizado no norte do Estado de M inas Gerais, vive um período de mudanças, que resultam em melhorias significativas. $\mathrm{No}$ entanto, ainda é perceptível a existência de uma prática iatrogênica-mutiladora. Vê-se que a prevenção e a promoção da saúde começam a vigorar entre as ações de saúde, que são vistas como importante fator para a melhoria da assistência à saúde bucal e consequente melhoria na qualidade de vida da população. Admite-se a necessidade de melhorar a inter-relação profissional/paciente, visto que o diálogo assume importante papel nessa inter-relação e faz com que o usuário se sinta valorizado com esse gesto, podendo contribuir na melhora do estado geral do paciente, bem como tornar o ambiente mais agradável, ganhando assim efetiva participação da população na resolução dos problemas relacionados à saúde bucal. $\mathrm{A}$ necessidade de se organizar e definir melhor a forma de acesso aos serviços é um importante aspecto observado no estudo. A forma de triagem dos pacientes precisa ser melhor definida, com a utilização de critérios bem estabelecidos. Consideramos relevante a necessidade de mais diálogo entre profissional e paciente, com este participando do planejamento das ações, bem como do seu desenvolvimento, visando melhor resolutividade das ações. Percebe-se a necessidade de criação de canais de comunicação com a população, fazendo com que sejam observados fatores relacionados ao seu cotidiano, seus anseios e angústias, para definição de estratégias eficazes e resolutivas relacionadas à saúde.

\section{Colaboradores}

BM Franco e $\mathrm{H}$ Martelli-Júnior participaram da coleta dos dados, da análise, discussão dos resultados, revisão da literatura e redação final do texto; LM P Ramalho eAA Santos participaram deste trabalho no processo de análise dos dados, bem como na orientação do trabalho. C Reis participou da coordenação do estudo, interpretação e análise e discussão dos resultados e redação final do texto. 


\section{Referências}

1. Araújo MAL, Leitão GCM. Acesso à consulta a portadores de doenças sexualmente transmissíveis: experiências de homens em uma unidade de saúde de Fortaleza, Ceará, Brasil. Cad. Saúde Pública 2005; 21:396-403.

2. Werneck MAFA. Saúde bucal no SU S: uma perspectiva de mudança [tese]. Niterói (RJ): Universidade Federal Fluminense; 1994.

3. Oliveira AGRC, Arcieri RM, Unfer B, Costa ICC, M oraes E, Saliba NA. M odelos assistenciais em saúde bucal no Brasil: tendências e perspectivas. Ação Coletiva 1999; 1:9-14.

4. Brasil. M inistério da Saúde. Secretaria de Políticas da Saúde - Área Técnica de Saúde Bucal. Plano de Reorganização da Saúde Bucal na Atenção Básica. Brasília: Ministério da Saúde; 2001.

5. Cordón JA. Sobre a construção histórica do conceito de Odontologia em saúde pública. Rev Assoc Odontologia em Saúde Coletiva 1998; 1:19.

6. Pinto VG. Saúde bucal coletiva. 4ạ ed. São Paulo: Editora Santos; 2000.

7. Martins EM. Saúde bucal, uma necessidade socialmente construída: um estudo da experiência da Clínica O dontológica São Geraldo [dissertação]. Belo Horizonte (M G): Universidade Federal de M inas Gerais; 1993.

8. Rego NC, Rego NGC, Silva Júnior OC, Silva DF. Programa de saúde em Odontologia: breves considerações básicas. RBO 1997; 54:565-567.

9. M inayo MCS. O desafio do conhecimento: pesquisa qualitativa em saúde. 7ạ ed. São Paulo: Hucitec; 2000.

10. Bosi MLM, Affonso KC. Cidadania, participação popular e saúde: com a palavra, os usuários da Rede Pública de Serviços. Cad. Saúde Pública 1998; 14:355-365.

11. Prefeitura Municipal de Grão Mogol. Secretaria de Saúde. Plano de Implementação das ESBs. Grão M ogol: Prefeitura Municipal; 2004.

12. Fédèration Dentaire Internationale. Global goals for oral health in the year 2000. International Dental Journal 1982; 32:74-77.

13. Souza DS, Cury JA, Caminha JAN, Ferreira MA, Tomita NE, Narvai PC, Gevaerd SP, M endes WB. A inserção da saúde bucal no Programa Saúde da Família. Rev. Bras. Odont. Saúde Coletiva 2001; 2:7-29.

14. Vasconcellos IC. Programas de saúde bucal: eficácia e perspectivas. RBO 2001; 58:130-134.

15. Nuto SS. Avaliação cultural do serviço de saúde bucal de Beberibe - CE: a vez e a voz do usuário [dissertação]. Fortaleza (CE): Universidade Federal do Ceará; 1999.
16. Viana G, Bandeira MAM, Matos T. Guia fitoterápico. Fortaleza: Secretaria da Saúde; 1998.

17. Cohn A, Nunes $E$, Jacobi PR, Karsch US. A saúde como direito e como serviço. São Paulo: Editora Cortez; 1991.

18. Bernd B, Souza CB, Lopes CB, Pires Filho FM, Lisbôa IC, Souza LNS, Pignone OA. Percepção popular sobre saúde bucal: o caso das gestantes do Valão. Saúde Debate 1992; 34:33-39.

19. Junqueira LAP, Auge APF. Qualidade dos serviços de saúde e satisfação do usuário. Revista da FUNDAP 1996; 19:60-77.

20. M inayo MCS. Saúde e doença: uma concepção popular da etiologia. Cad. Saúde Pública 1988; 4:356-362.

21. Brasil. M inistério da Saúde. Promoção de saúde: Carta de Otawa, Declaração de Adelaide, Sundsvall e Santa Fé de Bogotá. Brasília: Ministério da Saúde; 1996.

22. M inayo MCS. Na dor do corpo o grito da vida. In: Costa NR, M inayo MCS, Ramos CL, Stotz EM, Najar $A L$, Fonseca CMO, Duarte CMR, Oliveira JA de, Fiszon JT, Bodstein RCA, Siqueira SAV, Valla VV, organizadores. Demandas populares, políticas públicas de saúde. Petrópolis: Vozes; 1989.

23. Bosi ML, Affonso KC. Cidadania, participação popular e saúde na visão dos 33profissionais do setor: um estudo de caso na rede pública de serviços. Cad. Saude Publica 1994; 14:355-365.

24. Silva SRC, Fernandes RAC. Autopercepção das condições de saúde bucal dos idosos. Rev. Saúde Pública 2001; 35:349-355.

25. Bezerra JA, M arçal PH. Práticas empíricas odontológicas em Panamoá (DF) e Gurupi (TO) [monografia]. Brasília (DF): Universidade de Brasília; 1994.

26. Ramos FB. Como o paciente se sente ao ser atendido por um aluno de odontologia? Revista do CRO-M G 2001; 7:10-15.

27. Unfer B, Saliba O. Avaliação do conhecimento popular e práticas cotidianas em saúde bucal. Rev. Saude Publica 2000; 34:190-195.

Artigo apresentado em 01/08/2006

Aprovado em 13/04/2007

Versão final apresentada em 16/05/2007 